\title{
Caracterização e relacionamento antigênico de três novos Bunyavirus no grupo Anopheles A (Bunyaviridae) dos arbovirus*
}

\section{Characterization and antigenic relationship of three new Bunyavirus in the Anopheles $A$ serogroup (Bunyaviridae) of arboviruses}

\author{
Jorge Fernando Soares Travassos da Rosa*, Amélia Paes de Andrade Travassos da Rosa*\#, Nicolas \\ Dégallierm, Pedro Fernando da Costa Vasconcelos"t
}

\begin{abstract}
TRAVASSOS DA ROSA, J.F.S. et al. Caracterização e relacionamento antigênico de três novos Bunyavirus no grupo Anopheles A (Bunyaviridae) dos arbovirus. Rev. Saúde públ., S. Paulo, 26: 173-8, 1992. São descritos o isolamento e a caracterização de três novos arbovirus isolados na região da Usina Hidro-Elétrica de Tucuruf (UHE-TUC). Os três novos arbovirus pertencem ao grupo Anopheles A(ANA), genêro Bunyavirus (familia Bunyaviridae). Os vírus Tucuruí (TUC), Caraipé (CPE) e Arumateua (ART) são relacionados entre si e com o vírus Trombetas (TBT), formando dentro do grupo ANA um complexo chamado Trombetas. Os arbovirus TUC, CPE e ART foram obtidos a partir de lotes de mosquitos Anopheles (Nyssorhynchus) sp capturados em Tucuruí, nas proximidades da usina hidrelétrica de Tucuruí, Estado do Pará, nos meses de fevereiro, agosto e outubro de 1984, respectivamente. Até o final de 1990 os vírus TUC, CPE e ART foram isolados 12, 32 e 28 vezes respectivamente, sempre na região da UHE-TUC, exceção feita ao vírus TUC, do qual se obteve uma amostra procedente de Balbina, ande também foi construída uma hidroelétrica. Até o presente, esses virus só foram isolados a partir de mosquitos do grupo An. (Nys.) principalmente, a partir das espécies $A n$. (Nys.) nuneztovari e An. (Nys.) triannulatus também consideradas vetores secundários da malária na Amazônia Brasileira. Testes sorológicos executados com soros humanos e de diversas espécies de animais silvestres foram negativos, com exceção de um soro de um carnívoro de espécie Nasua nasua que neutralizou a amostra TUC em títulos de 2.6 índice logaritmico de neutralização (ILN).
\end{abstract}

Descritores: Bunyaviridae, isolamento. Anopheles, microbiologia

\section{Introduçäo}

O genêto Bunyavirus pertence à família Bunyaviridae que compreende mais de 200 vírus que infectam vertebrados e/ou invertebrados. Os Bunyavirus são vírus cujo acido nucléico é o RNA. Este apresenta aspecto linear de fita única, negativo, com configuração circular. Esses virus possuem uma enzima RNA transcriptase. A partícula viral apresenta-se sob a forma de nucleocapsideo com simetria helicoidal ou circular, com diâmetro variando de $2-12 \mathrm{~nm}$, e é envolta por um envelope lipoprotéico de 70

- Trabalho realizado com o apoio financeiro da Superintendencia de Desenvolvimento da Amazónia (SUDAM) e Centrais Elétricas do Notte do Brasil S.A. (ELETRONORTE).

** Centro Colaborador da Organização Mundial da Saúde (OMS) em Arboviroses, Instituto Evandro Chagas/Fundação Nacional da Saúde/Mfinistério da Saúde - Belém, PA - Brasil.

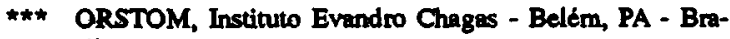
sil.

Separmag/Reprints: J.F.S. Travassos da Rosa - Av. Almirante Barroso, 492 - 66090-000 - Belém, PA - Brasil.
- $100 \mathrm{~nm}$ de dimensōes no maior eixo. A partícula integra possui de $90-100 \mathrm{~nm}$ de tamanho ${ }^{3}$.

Os Bunyavirus incluem o supergrupo $\mathrm{Bu}$ nyamwera, ao qual pertencem 18 grupos antigênicos, afora três vírus não grupados. Esses 18 sorogrupos têm sido grupados na base de reaçōes sorológicas cruzadas ${ }^{3}$. Dentre esses, está o grupo Anopheles A (ANA).

Os víns do grupo ANA são transmitidos predominantemente por mosquitos ${ }^{3,8}$. Neste grupo foram descritos até o presente 6 membros $^{8}$, sendo que 3 deles circulam há algum tempo na Amazônia Brasileira, a saber: Tacaiuma (TCM), Lukuni (LUK) e Trombetas (TBT), este último ainda não registrado. Com exceçäo do TCM, que causa uma síndrome febril aguda acompanhada de fortes dores musculares nos individuos acometidos, nenhum outro vírus tem sido incriminado como patógeno humano. O TCM, também se constitui no único tipo que possui hernaglutinina ${ }^{4}$.

No presente trabalho descreve-se 0 isolamento, caracterização e relacionamento antigêni- 
co de 3 novos membros do grupo ANA que foram isolados de mosquitos do grupo Anopheles (Nyssorhynchus), na área de abrangência da usina hidrelétrica de Tucuruí (UHE-TUC), Estado do Pará.

\section{Material e Método}

\section{Capturas}

As capturas foram realizadas utilizando-se as técnicas de isca humana com sucção oral e isca luminosa. As capturas com isca humana foram feitas nos horários de 8-12h e 14-18h, enquanto que os com isca luminosa de $19 \mathrm{~h}$ às $6 \mathrm{~h}$ da manhã seguinte, utilizando a armadilha tipo "Miniature CDC Light Trap". As viagens, das quais obtiveram-se os isolamentos, foram realizadas no ano de 1984, nos meses de fevereiro, agosto e outubro.

\section{Identificação e Inoculação dos Mosquitos}

Uma vez capturados, os mosquitos eram colocados em tubos criogênicos, rotulados com data, hora e local de coleta, bem como tipo de captura empregada. A seguir, eram imersos em nitrogênio líquido permanecendo assim até a identificação no laboratório, realizada sob refrigeração. Os mosquitos, após serem identificados por data, eram agrupados de acordo com espécie e sexo e a seguir macerados em gral de porcelana. O macerado, suspenso em uma solução fosfato tamponada de albumina bovina (fração V) contendo 200 unidades de penicilina e 200 ug de estreptomicina, centrifugado a 2.000 RPM. O sobrenadante, era finalmente inoculado $(0,02 \mathrm{ml})$ por via intra cerebral (ic) em camundongos albinos "swiss" recém nascidos $(1$ a 3 dias).

\section{Isolamento e Caracterização das Amostras}

Os camundongos inoculados eram observados diariamente, por 21 dias no biotério, fim dos quais eram eliminados se nảo apresentassem sinais de doença. Entretanto, se no decorrer desse periodo apresentavam-se doentes, eram colhidos para realização de passagem para estoque de vírus e realização de testes sorológicos para identificação. Os testes utilizados foram os de Fixação de Complemento (FC) em placas, de acordo com a técnica descrita por Fulton and Dumbell ${ }^{7}$, e Neutralização (N) em camundongos recémnascidos ${ }^{10}$, nos quais utilizaram-se cérebros de camundongos infectados como fonte de antígeno e vírus, respectivamente. Soros hiperimunes foram preparados em camundongos jovens, inoculados por via intra peritoneal a cada 7 dias com $0,2 \mathrm{ml}$ de suspensão de cérebros de camundongos infectados, diluídos em solução salina a $0,85 \%$, por 4 semanas. Sete dias após a quarta injeção, collheu-se sangue ${ }^{10}$.

\section{Resultados}

Em fevereiro de 1984 foi realizada viagem decorrente de convênio celebrado entre o Instituto Evandro Chagas (IEC) e a Superintendência do Desenvolvimento da Amazônia (SUDAM), através do Programas de Polos (POLOAMAZÓNIA), para coleta de dípteros hematófagos nas proximidades da UHE-TUC que estava então sendo construída (Fig. 1), quando se isolou uma

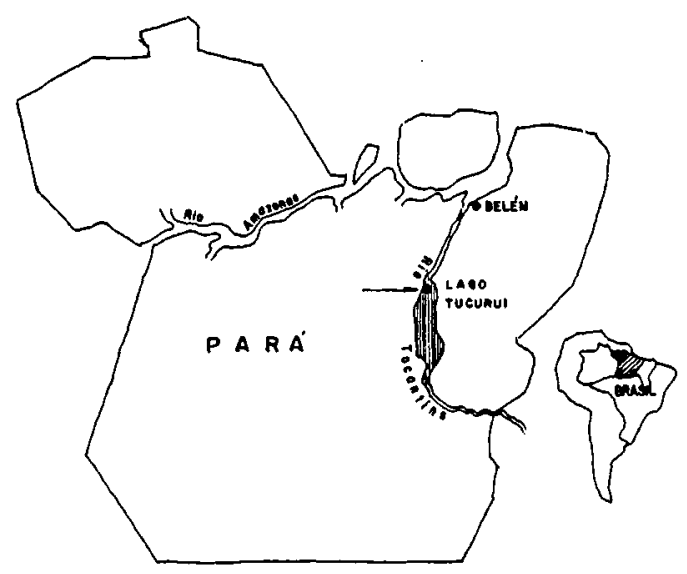

Figura 1. Mapa do local de isolamento original dos víns Tucuruí, Caraipé e Arumateua.

amostra de vírus, $B E$ AR 422535, identificada como pertencente ao grupo ANA a qual foi dada a denominação de Tucuruí (TUC). Em agosto do mesmo ano, outra viagem decorrente do convênio firmado entre o IEC e as Centrais Elétricas do Norte do Brasil S.A. (ELETRONORTE), foi realizada na área supracitada, no decorrer da qual foi isolada a amostra BE AR 428793. Ainda no mesmo ano, em outubro, se isolou de espécimes colhidos de uma terceira viagem ao mesmo local, o vírus BE AR 437811. Ambos foram identificados também como pertencentes ao grupo ANA e receberam os nomes de Caraipé (CPE) e Arumateua (ART), respectivamente. Todos os três vírus foram isolados a partir de lotes de mosquitos Anopheles (Nyssorhynchus) sp capturados através isca humana com sucção oral, em horários de 8 - $12 \mathrm{~h}$ e $14-18 \mathrm{~h}$. As três 
Tabela 1. Resultados dos testes de fixação de complemento cruzada entre os vírus do grupo Anopheles A.

\begin{tabular}{lcccccc}
\hline \multicolumn{1}{c}{ Antígenos } & Tucurui & Caraipé & Arumateua & Trombetas & Lukuni & Tacaiuma \\
\hline Tucurul & 64 & 256 & 0 & 256 & 8 & 0 \\
Caraipé & 64 & 256 & 0 & 256 & 64 & 0 \\
Arumateua & 0 & 8 & 32 & 8 & 0 & 0 \\
Trombetas & 32 & 256 & 0 & 64 & 0 & 0 \\
Lukuni & 0 & 32 & 0 & 8 & 16 & 0 \\
Tacaiuma & 0 & 0 & 0 & 0 & 0 & 64 \\
\hline
\end{tabular}

Tabela 2. Resultados dos testes de neutralização cruzada* em camundongos entre os vírus do grupo Anopheles A.

\begin{tabular}{lcccccc}
\hline \multicolumn{1}{c}{ Vírus } & Tucurui & Caraipé & Arumateua & Trombetas & Lukuni & Tacaiuma \\
\hline Tucurui & $4,5^{*}$ & $<0,8$ & $<0,8$ & 0 & 0,9 & $<1,1$ \\
Caraipé & $<0,5$ & $>3,8$ & 0,4 & 0 & $<0,6$ & 0 \\
Arumateua & $<0,2$ & $<0,3$ & 3,7 & $<0,2$ & $<0,8$ & $<1,1$ \\
Trombetas & 0 & 0 & 0 & $>2,9$ & 0 & 0 \\
Lukuni & $<1,1$ & $<1,1$ & $<1,1$ & $<1,1$ & $>4,1$ & $\mathrm{NT}$ \\
Tacaiuma & $<2,0$ & $<2,0$ & $<2,0$ & $<2,0$ & $<2,0$ & 7,2 \\
\hline
\end{tabular}

: Expressos em índice logarítmico de neutralização

NT: Não testado

amostras isoladas por FC não reagiram com soros imunes de 160 arbovírus previamente isolados pelo IEC na região Amazônica Brasileira, bem como com soros hiperimunes de grupos e polivalentes de arbovirus adquiridos no National Institute of Health (Bethesda, Maryland, USA). Mas reagiram entre si e com o tipo TBT (BE AN 306770), isolado a partir das vísceras de um ungulata da espécie Tayassu pecari, capturado em Porto Trombetas, Município de Oriximiná, Pará, em fevereiro de 1976 (Tabela 1). Seus antígenos extraídos por sucrose-acetona não produziram hemaglutinina. Por N (Tabela 2), utilizando comundongos recém-nascidos como siste$\mathrm{ma}^{10}$ e realizado em duplo sentido com as novas amostras e outros membros do grupo ANA, os resultados mostraram que os três vírus constituem novos tipos. Submetidos a teste de sensibilidade pelo desoxicolato de sódio (DCA) ${ }^{11}$, os resultados mostraram que os mesmos são sensíveis, embora um deles (TUC) tenha ficado no limiar do mínimo preconizado (Tabela 3).

Os tipos TUC, CPE e ART foram isolados sistematicamente nos anos subseqüentes sendo que, até 1990, foram obtidos 12,32 e 28 vezes, respectivamente, a partir de mosquitos Anopheles (Nyssorhynchus) triannulatus e Anopheles (Nyssorhynchus) nuneztovari, bem como de lotes mistos de An. (Nys.) oswaldoi e An. (Nys.) nuneztovari (Fig. 2).
Tabela 3. Resultados dos testes de resisténcia ao $D C A$, realizados em camundongos, com vírus do grupo Anopheles A.

\begin{tabular}{lcc}
\hline & \multicolumn{2}{c}{ Titulação } \\
Virus & DCA & Controle \\
\hline Tucurui & 1,5 & 3,3 \\
Caraipé & 0,5 & 3,0 \\
Arumateua & 1,2 & 3,5 \\
\hline
\end{tabular}

\section{Discussão}

Os vírus do grupo ANA têm sido isolados somente nas Américas do Sul (Argentina, Brasil e Colombia) e Central (Trinidad e Panamá) $)^{3,4,5,8}$

$O$ isolamento de três novos tipos dentro do grupo ANA, em um mesmo local e em um mesmo ano, em meses diferentes, é relevante, pois esses vírus desde então têm-se mantido altamente prevalentes, revelando um caráter enzoótico na regiāo da UHE-TUC. Esses três arbovírus parecem ter distribuiçäo focal, tendo sido encontrados somente em Tucuruí, à exceção do vírus TUC que foi uma única vez isolado em Balbina, onde também existe lago formado pela barragem do rio Uatumã, no norte do Estado do Amazonas, em decorrência da construção de usina hidrelétrica.

Todos os isolamentos têm sidó obtidos uni- 

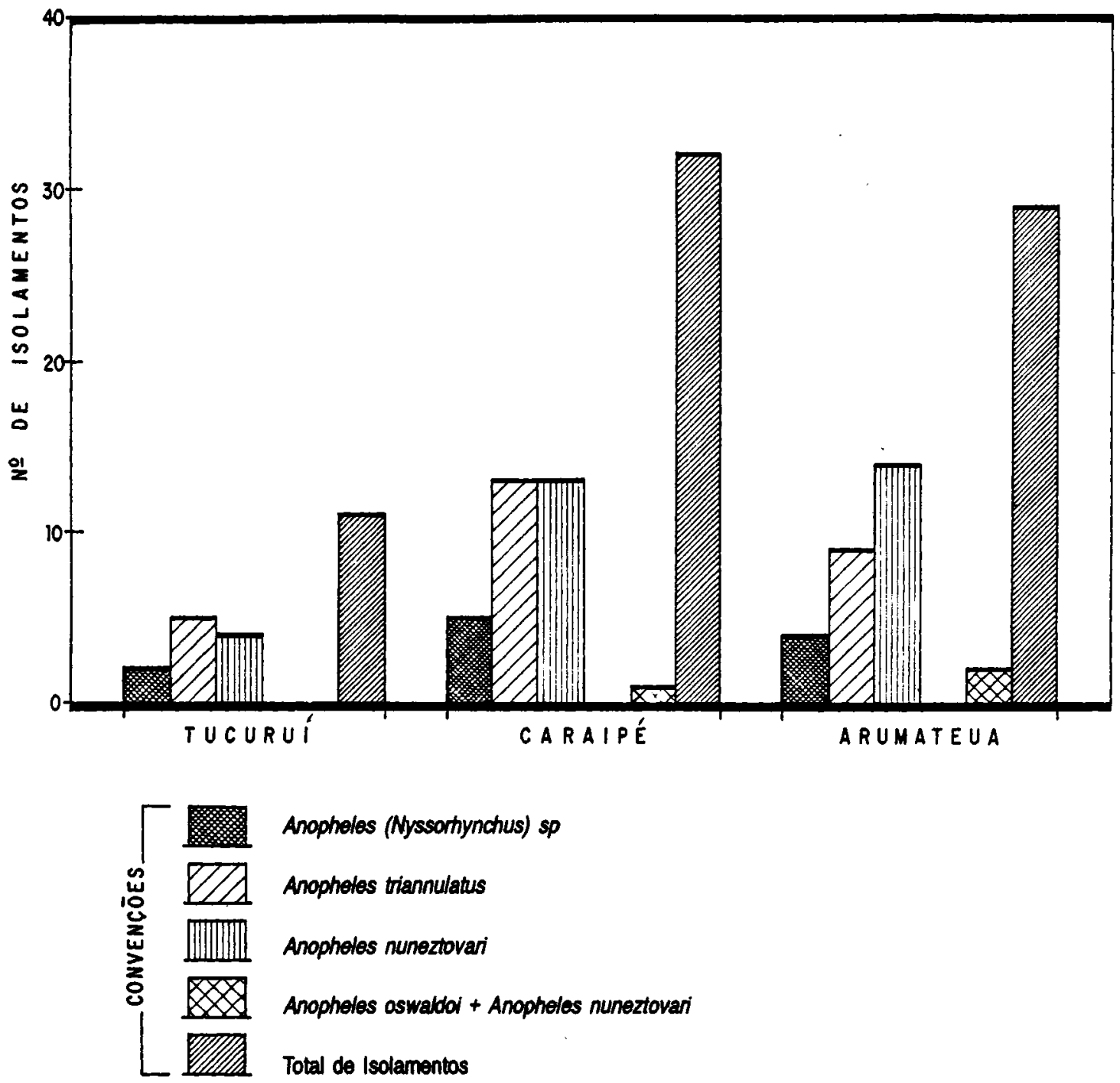

Figure 2. Distribuiça dos isolamentos dos virus Tucurui, Carajpé, Arumateua de acordo com a espécie de mosquito do grupo Anopheles (Nyssomynchus).

camente de mosquitos do grupo Anopheles (Nyssorhynchus), principalmente das espécies An. (Nys.) triannulatus e An (Nys.) nuneztovari (Fig. 2). Tais artrópodes, que já eram prevalentes antes da formação do lago na UHE-TUC, proliferaram significativamente após o fechamento das comportas em 1 de setembro de 1984. Esses anophelinos sāo amplamente distribuídos e tidos como vetores secundários da malária na Regiāo Amazônical. Por outro lado, a despeito de até 0 momento nenhum caso de doença humana atribuído aos vírus TUC, CPE e ART ter sido registrado, esses vínus podem se tornar importantes patógenos hnmanos, se considerarmos a elevada densidade populacional de mosquitos do grupo Anopheles (Nyssorhynchus), seus transmissores, em áreas próximas ao reservatório de Tucuruí.

Testes de $\mathrm{N}$ realizados em camundongos com soros humanos e de diversas espécies de animais procedentes da região da UHE-TUC desafiando esses novos arbovirus -, foram negativos, exceto para o soro de um carnívoro Nasua nasua que neutralizou a amostra TUC, em título de $2.6 \mathrm{ILN}$. Os resultados obtidos por $\mathrm{N}$ e a ausência de isolamentos a partir de animais silvestres da área estudada impossibilitou até o presente conhecer a ecoepidemiologia desses agentes virais, bem como seus ciclos de manutenção.

Esses três tipos; TUC, CPE e ART, formam 
juntamente com o vírus TBT um complexo dentro do grupo ANA, o qual propöe-se chamar de complexo Trombetas, devido o vírus TBT ter sido o primeiro tipo isolado. A formaçäo de complexos dentro desse grupo antigênico parece ser uma caracteristica marcante, haja vista que outros tipos, quais sejam, Tacaiuma e Anopheles A, formam com outros vírus a eles relacionados os complexos Tacaiuma e Anopheles A, respectivamente ${ }^{3,4}$. Nesse complexo Trombetas, o tipo mais afastado é o ART, que por FC (Tabela 1) reage fracamente com soros imunes do TBT e CPE e não reage com o TUC. Os outros três vírus TBT, CPE e TUC, ainda por FC, não reagem com o soro do ART, mas reagem fortemente entre si nos dois sentidos, porém são completamente distintos por $\mathrm{N}$ (Tabela 2).

Estudos posteriores sâo necessários para tentar elucidar o ciclo biológico de manutenção desses agentes, principalmente no que diz respeito aos seus hospedeiros silvestres e sua possibilidade de causar doença no homem e em animais de importância em saúde veterinária. Devemos ter em conta que o Município de Tucuruí possui aproximadamente 100.000 habitantes, cuja população tem, nas atividades agropecuárias, as principais fontes de trabalho e arrecadação. Assim, medidas de controle e combate aos vetores, também responsáveis pela transmissão da malátia na região, fazem-se necessárias com o intuito de impedir a disseminação daqueles mosquitos e dos vírus na região.

\section{Agradecimentos}

A ELETRONORTE, pelo apoio logistico e financeiro; à SUDAM pelo auxílio financeiro; e aos funcionários da Seção de Arbovírus do Instituto Evandro Chagas, especialmente os do Laboratớrio de Entomologia.

\section{TRAVASSOS DA ROSA, J.F.S. et al.}

[Characterization and antigenic relationship of three new Bunyavirus in the Anopheles A serogroup (Bunyaviridae) of arboviruses]. Rev. Saúde públ., S. Paulo, 26: 173-8, 1992. The isolation and characterization of three new viruses obtained from the Tucurui hydroelectric dam region is reported. These three agents belong to the Anopheles $A$ serogroup, genus Bunyavirus, Bunyaviridae. The Tucuruí (TUC), Caraipé (CPE) and Arumateua (ART) viruses have close relationships with each other and with Trombetas (TBT) virus, an Anopheles A virus previously isolated in the Amazon Region of Brazil. These viruses form the "Trombetas complex". TUC, CPE and ART viruses were obtained from pools of Anopheles

(Nyssorhynchus) sp captured in Tucurui, Pará State, in February, August and October of 1984, respectively. Until 1990 TUC, CPE and ART were isolated 12,32 and 28 times respectively, in the Tucurui hydroelectric dam region. At the moment, these viruses have only been obtained from mosquitoes of the Anopheles (Nyssorhynchus) complex, especially from An. (Nys.) nuneztovari and $A n$. (Nys.) triannulatus, that are considered to be secondary vectors of Plasmodium in Amazonia. Serological tests performed with human and wild animal sera were negative, except for one specimen Nasua nasua that had neutralization antibodies to TUC.

Keywords: Bunyaviridae, isolation. Anopheles, microbiology.

\section{Referências Bibliográficas}

1. ARRUDA, M.; CARVALHO, M.B.; NUSSENZWEIR, RS.; MARACIC, M.; FERREIRA, A.W.; COCHRANE, A.H. Potential vectors of malaria and their different susceptibility to Plasmodium falciparum and Plasmadium vivax in Northem Brazil identified by immunoassay. Amer. J. trop. Med Hyg. 35: 873-81, 1986.

2. BISHOP, D.H.L.; CALISHER, C.H.; CASALS, J.; CHUMAKOV, M.P.; GAIDAMOVICH, S.Ya.; HANNOUN, C.; LVOV, D.K.; MARSHAL, I.D.; OKERBLOM, N.; PATTERSON, R.F.; PORTERFIELD, J.S.; RUSSELL P.K.; SHOPE, R.E.; WESTAWAY, E.G. Bunyaviridae. Intervirology, 14: 125-43, 1980.

3. CALISHER, C.H.; SASSO, D.R.; MANESS, K.S.C.; GHEORGHIV, V.N.; SHOPE, R.E. Relationships of Anopheles A group arbovirus. Proc. Soc. exper. Biol. Med, 143: 465-8, 1973.

4. CALISHER, C.H.; LAZUICK, J.S.; MUTH, D.J.; LOPES, O.S.; CRANE, G.T.; ELBEL, R.E.; SHOPE, RE. Antigenic relationships among Tacaiuma complex viruses of the Anopheles A Serogroup (Bunyaviridae). Bull. Pan. Amer. Hlth Org, 14: 386-91, 1980.

5. CALISHER, C.H.; MONATH, T.P.; MTTCHELL, C.J.; SABATTINI, M.S.; CROPP, C.B.; KERSCHNER, J.; HUNT, A.R; LAZUICK, J.S. Arbovirus Investigations in Argentina, 1977-1980. III Identification and characterization of viruses isolated, including new subtypes of Western and Venezuelan Equine Encephalitis viruses and four new Bunyaviruses (Las Maloyas, Resistencia, Barranqueras and Antequera). Amer. J. trop. Med. Hyg., 34: 956-65, 1985.

6. DEGALLIER, N.; TRAVASSOS DA ROSA, A.P.A; HERVÉ, J. P.; VASCONCELOS, P.F.C.; TRAVASSOS DA ROSA, J.F.S.; SÁ FILHO, G.C.; PINHEIRO, F.P. Modifications of arbovins eco-epidemiology in Tucurui, Para, Brazilian Amazonia, related to the construction of a hydroeletric dam. In: Uren, M.F.; Blok, J.; Manderson, K.H., ed. Arbovirus research in Australia; Proceedings Sth Symposium. Brisbane, Australia, Queensland Institute of Medical Research, 1989. p. 124-35.

7. FULTON F. \& DUMBELL, K.R. The serological comparison of strains of Influenza virus. J. gen. Microbiol., 3: 97-111, 1949. 
8. KARABATSOS, N., ed. Insernational catalogue of arboviruses including certain other viruses of vertebrates. 3rd od. San Antonio, American Society of Tropical Medicine and Hygiene, 1985.

9. PINHRIRO, F.P.; TRAVASSOS DA ROSA, A.P.A.; FRETTAS, R.B.; TRAVASSOS DA ROSA, J.F.S.; VASCONCELOS, P.F.C. Arboviroses: aspectos clínico-epidemiológicos. In: Instituto Evandro Chagas, 50 anos de contribuiģo ds ciências biológicas e a medicina tropical Belém, Fundação Serviços de Saúde Pública. 1986. v. 1, p. 375-408.
10. SHOPE, RE. \& SATHER, G.E. Atborinuses. In: Lennette, EH. \& Schimdt, N.J., ed. Diagnostic procedures for virah rickettsial and chlamydial infections. Sth ed. Washington, DC, American Public Health Association, 1979. p. 767-814.

11. THEILER, M. Action of sodium desoxycholate on arthropod-bome viruses. Proc. Soc. exper. Biol. Med, 96: 380-2, 1957.

Recebido para publicaçāo em $8 / 10 / 1991$

Reapresentado em 25/2/1992 Aprovado para publicação em 27/2/1992 